\title{
Features of the physical and chemical characteristics of water of energy facilities for aquaculture tasks
}

\author{
Marina Kalaida ${ }^{1}$, and Maria Gordeeva ${ }^{1, *}$ \\ ${ }^{1}$ Kazan state power engineering university, Water bioresources and aquaculture Department, 420066 Krasnoselskaya, 51, Russia
}

\begin{abstract}
Energy facilities and water are inextricably linked. Accordingly, the issue of water quality, its transformation as a result of industrial use of energy facilities and the assessment of further use for aquaculture purposes is an urgent task of our time, especially in relation to weather and climate risks for industries. The article provides a classification of water according to the water supply technology of energy facilities by temperature factor and the possibility of using it for aquaculture tasks. In total, three classes of water are distinguished according to the temperature factor: waters with natural physical and chemical characteristics, where the temperature regime of reservoirs corresponds to the geographical zone in which the reservoir is located (cultivation of fish associated with fish-breeding zone in which the reservoir is located); water of bassin-coolers of energy facilities, characterized by the presence of a zone of increased temperatures as a result of the discharge of heated water (organization of flood-proof farms with polycyclic production); water of cooling ponds (cultivating fish capable to the fight against eutrophication).
\end{abstract}

\section{Introduction}

Water ecosystems are a source of water for humans and industry, so they are multi-purpose objects of using. This article investigates water ecosystems as an integral component of energy facilities. The World Energy Council estimated the amount of water consumption for energy production at 583 billion $\mathrm{m} 3$, which is about $15 \%$ of the total water consumption in the world. The volume of irretrievably used water amounted to 66 billion $\mathrm{m} 3$. This problem (water consumption and as a result water quality) is one of the priorities to date and is being discussed in the world scientific community, especially in China [1-3]. According to the International Energy Agency's global energy scenario, water intake increased by about $20 \%$ between 2010 and 2015 , and water use (including re-use) increased to $85 \%$. All this leads to the need to understand the possibilities and ways of sharing water for industrial needs and for household (food). This issue is particularly relevant in the context of ongoing climate change.

To date, the economic damage from climate change is estimated at $\$ 1.2$ trillion per year (in 2012 prices), or $1.6 \%$ of global GDP [4-7]. In Russia, because of its northern location, the climate is warmer faster than in the rest of the world. According to Yu. A. Izrael institute of global climate and ecology of federal service for hydrometeorology and environmental monitoring and Russian academy of sciences, the growth rate of average annual temperature in Russia is 2.5 times higher than the global average, and in the Northern Polar Region - 4 times.
The report on climate risks in the territory of Russian Federation (2017) provides estimates of the impact of climate and meteorological factors on life and health, the state of infrastructure facilities, agriculture and forestry, which indicate that agriculture $(30 \%)$ are more at risk in the Volga Federal District, than energy and social sector $(20 \%)$. Fisheries, transport and the mining industry $(10 \%)$ are closing the chain of risk in the Volga Federal District [8].

This raises questions about the possibility of using natural waters involved in the operation of energy facilities for aquaculture tasks. It is necessary to understand that in aquaculture the main indicator for the selection of the fish breeding is the temperature factor. In addition, for the successful reproduction and fish breeding it is necessary to organize the continued monitoring of such physicochemical characteristics as dissolved oxygen concentration, $\mathrm{pH}$. Numerous researches conducted at the Department of Water bioresources and aquaculture of Kazan State Power Engineering University allow us to propose redox potential and total antioxidant activity as promising physicochemical indicators.

\section{Materials and methods}

Data collection on physical and chemical characteristics of water in natural reservoirs, including the reservoirs of energy facilities, of the Republic of Tatarstan was carried out from 2010 to the present time.

The redox potential (Eh) and $\mathrm{pH}$ were measured by the ionomer I-160 MI. According to the certificate of this device, Eh is measured by combined electrode and a

\footnotetext{
* Corresponding author: Maria.Galeeva@gmail.com
} 
comparison electrode. The combined electrode has a glass body with a diameter of $12 \mathrm{~mm}$. In its lower part of device there is a working membrane sensitive to hydrogen ions, which is a ball made of special glass. Porous ceramic is soldered above the ball, providing electrolytic contact between the electrolyte poured into the electrode and the analysed solution. The upper part of the electrode ends with a sleeve, from which a cable comes out with a connector for connection to the converter.

Total antioxidant activity (TAOA) was determined by culonometric method using electrogenerated bromine. Samples were analyzed on the Expert-006 coulometer (Ekonix-Expert LLC, Russia) using a certified methodology. Electricity generation of bromine was carried out from a $0.2 \mathrm{M}$ solution of potassium bromide in a $0.1 \mathrm{M}$ aqueous solution of sulfuric acid at a constant current strength of $100.0 \mathrm{~mA} .30 \mathrm{ml}$ of the background solution was introduced into the electrolytic cell and when the test current reached a certain value, an aliquot of the aqueous extract of the test sample of $100 \mathrm{mkl}$. The determination was carried out at room temperature. The device was calibrated with an alcoholic solution of the Russian standard sample (RSS) of the routine prepared according to the current State Pharmacopoeia of the XI edition. TAOA was expressed in $\mathrm{mg}$ of a standard rutin $(\mathrm{Ru})$ sample per $1 \mathrm{dm}^{3}$ of extraction or in $\mathrm{g}$ of $\mathrm{Ru}$ per $100 \mathrm{~g}$ of test sample.

Statistical processing of obtained results was carried out through modal value (mode) of 10 definitions, relative error of determination of TAOA of tested samples (E relative) was within 3.0-5.0\%.

The dissolved oxygen concentration and water temperature were determined by oximeter «Mark 302E».

All collected data were statistically processed using Microsoft Excel and Statgraphics Plus 5.1.

\section{Results and discussions}

The change in the temperature regime of the regions leads to a change in the objects of cultivation [9-11], therefore, it is necessary to understand to which fishbreeding zone reservoir belongs where the object of energy is located and is planned for aquaculture purposes.

For example, in 1986, the Tatar ASSR was classified to two fish-breeding zone with a number of days per year with an air temperature of more than $15^{\circ} \mathrm{C}$ from 76 to 90 . Currently, according to the calculations, the Republic of Tatarstan can be attributed to 5 fish-breeding zone (121135 degree-days) (Fig. 1) [12]. Thus, in about 30 years there has been changed to 3 positions.

An additional increase the water temperature occurs due to the discharge of heated water of thermal power plants, which also leads to changes in the choice of both the breeding object and the conditions of cultivation.

However, the work of not all energy facilities leads to a change in the temperature of the aquatic ecosystem, which is a source of water. Accordingly, it is necessary to classify the waters used for energy purposes by temperature factor.

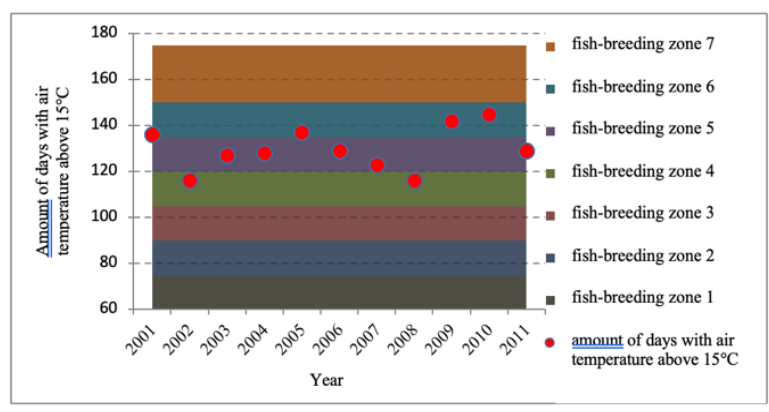

Fig. 1. Number of days per year with an air temperature above $15^{\circ} \mathrm{C}$ in the last 11 years in the Kazan city.

Suppose that the 1st class is the water with natural physical and chemical characteristics, that is the temperature condition of the reservoir in this case will correspond to the geographical area in which the reservoir is located. An example of possible energy facilities: hydroelectric power plants. In this case, the choice of aquaculture object will be determined by the fish-breeding zone in which the reservoir is located. For example, in the Republic of Tatarstan it is the Nizhnekamsk hydroelectric power plant, located on the Kama River. The temperature condition of water mass has a stable annual cyclicality. The average water temperature in the summer time is $23^{\circ} \mathrm{C}$. From 2018 to 2020, more than 100 rivers of the Republic of Tatarstan were investigated to analyze the dynamics of the redox potential of water. It was found that the range of change of Eh is from $-21.1 \mathrm{mV}$ to $-166.1 \mathrm{mV}$. The average value of the Eh in the Kama River is $-86.3 \pm 2.5 \mathrm{mV}$ in the summer. In a comparative aspect, the value of the redox potential of the Kama River with other large rivers of the Republic of Tatarstan is shown in Fig. 2 [13].

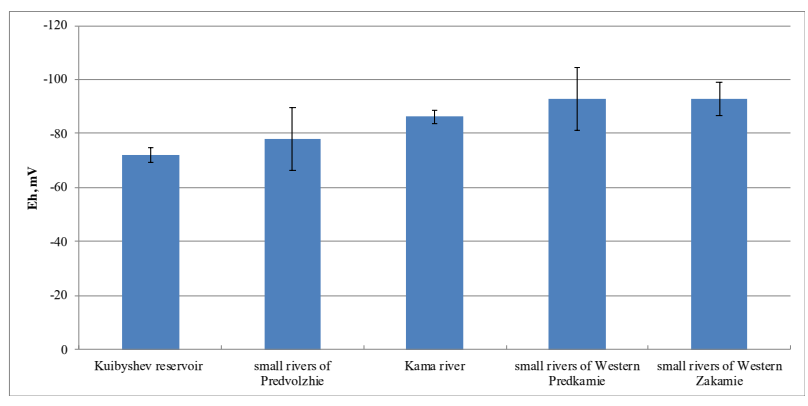

Fig. 2. Dynamics of redox potential in the large rivers of the Republic of Tatarstan [13].

Knowing the Eh values of water, it is necessary to understand the suitability of the obtained values for aquaculture purposes. In this regard, a series of experiments on carp fish species were carried out. It was revealed that for carp fish, the oppression zone lies in the ranges from -176 to $-282 \mathrm{mV}$ and from -2 to $80 \mathrm{mV}$; zone of normal existence from -2 to $-176 \mathrm{mV}$; the zone of optimal values is included in the zone of normal existence and corresponds to the values of $\mathrm{Eh}$ in the range from -59 to $-149 \mathrm{mV}$. Thus, the Eh values of the Kama River are located in the zone of optimal existence for carp fish species, which makes this reservoir attractive for aquaculture tasks. 
Another promising physical and chemical indicator is total antioxidant activity [14]. The research carried out at the Department of Water Bioresources and Aquaculture of Kazan state power engineering university allowed to identify 9 clusters of TAOA with different chemical characteristics:

Cluster №1 - $7.5469 \mathrm{mg}$ Ru per $1 \mathrm{dm}^{3}$;

Cluster №2 - $6.8212 \mathrm{mg}$ Ru per $1 \mathrm{dm}^{3}$;

Cluster №3 - 6.0956 mg Ru per $1 \mathrm{dm}^{3}$;

Cluster №4 - $5.3699 \mathrm{mg}$ Ru per $1 \mathrm{dm}^{3}$;

Cluster №5 - $4.6443 \mathrm{mg}$ Ru per $1 \mathrm{dm}^{3}$;

Cluster №6 - $3.9912 \mathrm{mg}$ Ru per $1 \mathrm{dm}^{3}$;

Cluster №7 - $3.2655 \mathrm{mg} \mathrm{Ru}$ per $1 \mathrm{dm}^{3}$;

Cluster №8 - $2.4673 \mathrm{mg}$ Ru per $1 \mathrm{dm}^{3}$;

Cluster №9 - $1.8142 \mathrm{mg}$ Ru per $1 \mathrm{dm}^{3}$.

Since the structure of natural waters differed in the different percentage of clusters, which were characterized by different values of the TAOA of water, a water structure index is proposed (Fig. 3):

$$
I w s=(F \times T A O A) \times C t / A
$$

where, F - Frequency of occurrence of water cluster (in shares);

TAOA - the value of total antioxidant activity (mg Ru per $1 \mathrm{dm}^{3}$ );

$\mathrm{Ct}$ - coefficient of trophy $(0.5-$ dystrophic reservoirs; 1 - oligotrophic reservoirs; 2 - mesotrophic reservoirs; 3 - eutrophic reservoirs);

$\mathrm{A}$ - number of selected clusters in the sample.

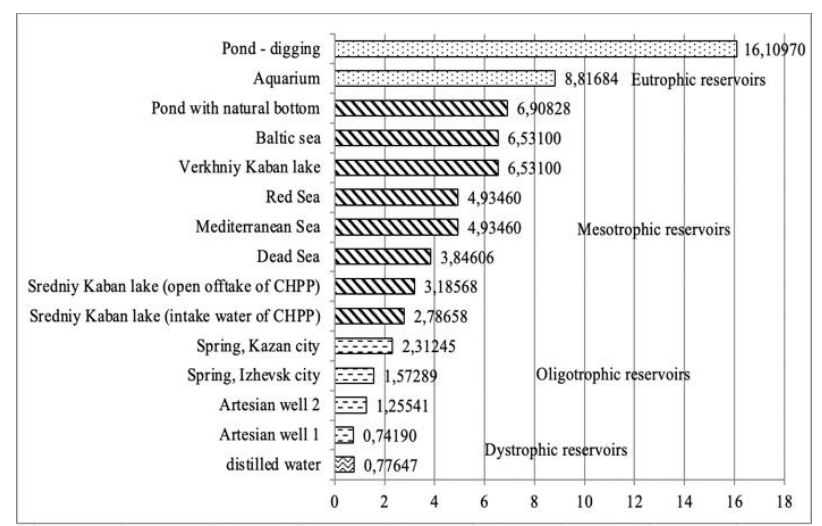

Fig. 3. Water classification according to the Index of water structure.

In general, the Kama River can be described as mesotrophic in the level of trophies. According to this index of the water structure, the water in the Kama River will approach the values of 5-7.

Class 2 is the water of bassin-coolers of energy facilities, characterized by the presence of a zone of increased temperatures as a result of the discharge of heated water. An example of possible energy facilities: state district power plants (GRES) or thermal power plants (CHP) with a direct-flow water supply system. As a result of artificial impact on the ecosystem of the reservoir in the temperature annual mode the disappearance of the winter stagnation period, the extension of the thermocline period (2 months: July, August) is characteristic. The discharge of heated waters does not allow the average temperature to drop below $4^{\circ} \mathrm{C}$ in winter time. It is in the winter we can see the maximum difference in temperature values relative to the temperature background is observed (up to $11^{\circ} \mathrm{C}$ ) $[12,15]$. In general, the thermal condition of these reservoirs can be characterized as unstable and dependent on the operation of energy facilities [16], with an increase in the water temperature in the summer period up to $3^{\circ} \mathrm{C}$ relative to the temperature background and in the winter period up to $11^{\circ} \mathrm{C}$. Redox potential values range from $\quad-70 \mathrm{mV}$ [17]. This value indicates a supportive environment for the hydrobionts breeding similar to the 1 class. The water structure index ranges from 2.7 to 3.2. Low index values can be characterized by the use of artesian or spring waters, as it observed at the Zainskaya GRES (mixed source water: the Kama River and the artesian well) and the Kazan CHP-1 (spring makeup of the Lake Sredniy Kaban [12, 18]). A suitable form of fish farming under such conditions is preferably flood-proof houses. Based on the described physicochemical characteristics, these reservoirs are characterized by the cultivation in summer period the fish which less demanding to environmental conditions and possibly having specialized organs for breathing with atmospheric air. It is generally accepted that carp is a less demanding object of aquaculture for environmental conditions. However, in 2016, as a result of abnormally hot summers, $100 \%$ of fish deaths in flood-proof farms were recorded at the Zainsky reservoir (for one night, mortality was 170 tons of carp).

In this regard, it is advisable to consider as an aquaculture object for a given class of reservoirs of clarium catfish, which has an above-gill organ, due to which it is capable of breathing atmospheric air. High planting densities of fish grown in flood-proof houses and intensive feeding on them with artificial feed increase the number of organic substances, discharge of heated waters leads to an increase in the average temperature in the reservoir, all this contributes to accelerated eutrophication of the reservoir. With an increase in the trophy of the reservoir, the water structure index will grow and reach 7-8, while the number of TAOA clusters found in the water will decrease (Fig. 3 and 4).

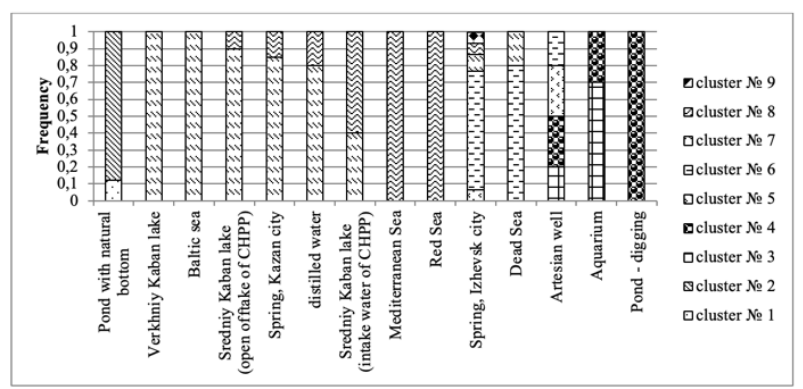

Fig. 4. Water clusters of various water bodies according to the total antioxidant activity.

As we can see on the Figure 4 the simplified (one cluster of water) water structure is possessed by the waters of fish ponds with spring feeding, lakes with 
weak anthropogenic effects, while the mode of TAOA is the maximum of the researched.

In winter, it is advisable to organize flood-proof of a trout houses: the water temperature is suitable, the concentration of oxygen due to the lack of ice cover and the circulation of water during the passage of the discharge channel reaches the desired values (up to 10 $\left.\mathrm{mg} / \mathrm{dm}^{3}\right)$. Thus, this class of water allows you to organize polycyclic production: in winter, the cultivation of salmon with an optimal temperature of $12-15^{\circ} \mathrm{C}$, and in summer - heat-loving fish species with a temperature optimum of $26-30^{\circ} \mathrm{C}$, for example, clarium catfish.

Class 3 is the water of cooling ponds. An example of possible energy facilities: thermal power plants operating on a recycled type of technical water supply, nuclear power plants (NPP) [19-21]. This type of water supply occurs in the absence of a reservoir of the necessary capacity, in which case water is pumped to cool the mechanisms and then returned to the artificial cooler. Cooling towers and cooling ponds can act as cooler. Artificial pools are used to remove small amounts of heat, up to about $200.000 \mathrm{kcal} /$ hour, which requires an area of $800-1000 \mathrm{~m}^{2}$. The artificial pond can be created in 2 ways, in the first case the design feature is the waterproof of the walls and the bottom, it is made in the form of round or rectangular open reinforced concrete tanks located in the recess. Under these conditions, aquaculture tasks are difficult to achieve due to watertight walls, as a result of which constant circulation and replenishment with fresh water is required to avoid acidification of water by accumulating high concentrations of organic compounds (both fodder residues and life products). In this case, in a short period of time, the redox potential values will reach positive values, while in 1 and 2 of the water class described, the Redox potential values were $-70-80 \mathrm{mV}$. As we said earlier, positive values of the redox potential indicate a fall into the zone of oppression and death for carp fish. Nowadays, such artificial basins are increasingly used to cool water due to their high cost and preference is given to the creation of artificial ponds by fencing the river bed with platinum. Such ponds-reservoirs on rivers combine the functions of a cooler and a drain regulator. The depth ranges from 1,5 to 3 meters. These artificial reservoirs are also subject to eutrophication processes and the Redox-potential values will reach -120-160 mV, while the water structure index can reach maximum values (from 9 to 16), and the number of TAOA clusters is minimal (most often 1, Fig. 4). Eutrophication processes can be controlled by the correct selection of hydrobionts for aquaculture purposes.

\section{Conclusion}

Despite the difference in the temperature regime of the described classes of water and other physicochemical indicators, with the correct selection of biotechnologies, any water can be used. The most suitable water class for aquaculture purposes can be considered 2 - these are the waters of the basin-coolers of energy facilities, characterized by the presence of an elevated temperature zone as a result of the discharge of heated waters. In this case, it is possible to organize polycyclic production and expansion of aquaculture objects, affecting both heatloving (in the summer) and cold-loving (in the winter) fish species. At the same time, the values of the main physicochemical parameters, such as the concentration of dissolved oxygen (in the summer), Redox-potential, the associated indicator $\mathrm{pH}$ are identical to the values in natural reservoirs without thermal influence, and in the winter period the concentration of dissolved oxygen is higher compared to reservoirs without thermal effect.

\section{References}

1. G. He, H. Liu, J. Wang, Y. Zhao, Y. Zhu, S. Jiang, H. Li, J. Zhai, F. He, Energy-water security challenge: Impact of energy production on water sustainable developments in Northwest China in 2017 and 2030, 766 (2021)

2. X. Zheng, G. Huang, J. Li, L. Liu, X. Zhang, X. Pan, Development of a factorial water policy simulation approach from production and consumption perspectives, 193 (2021)

3. M. Zhao, G. Jiang, G. Ming, Q. Su, L. Ma, Analysis of the driving forces for changes in a regional energy sector's water consumption, $\mathbf{3}$, 103-109 (2020)

4. D.A. Soloviev, Water resources and energy production, 8, 13-21 (2017)

5. S.R. Meckler, Causes and Impacts of Deficient Liability for Climate Change Damage, and an Economic Conception for Climate Change Liability That Supports Appropriate Action: DRaCULA, 135, 288-298 (2017)

6. Z. Zhao, X. Chen, C. Liu, F. Yang, X. Tan, Y. Zhao, H. Huang, C. Wei, X. Shi, W. Zhai, F. Guo, B. Ruijven, Global climate damage in $2{ }^{\circ} \mathrm{C}$ and $1.5{ }^{\circ} \mathrm{C}$ scenarios based on BCC_SESM model in IAM framework, 11, 261-272 (2020)

7. Y. Chen, L. Aobo, X. Cheng, Quantifying economic impacts of climate change under nine future emission scenarios within CMIP6, 703 (2020)

8. Report on climate risks in the Russian Federation (St. Petersburg, 2017)

9. D. Kar Community-based Fisheries Management, A Global Perspective (Academic Press, 2021)

10. R. Ogutu-Ohwayo, V. Natugonza, L. Musinguzi, M. Olokotum, S. Naigaga, Implications of climate variability and change for African lake ecosystems, fisheries productivity, and livelihoods, 42, 498-510 (2016)

11. K. Brander, Impacts of climate change on fisheries, 79, 389-402 (2010)

12. M.E. Gordeeva, M.L. Kalaida, Integrated assessment of the ecosystem of lakes, Urbanized areas (Lap Lambert Academic Publishung, 2015) 
13. M.E. Gordeeva, M.L. Kalaida, Using Redox potential in water quality assessment of energy facilities, IOP Conf. Series: Earth and Environmental Science, 288, 012039 (2019)

14. A.A. Lapin, M.E. Gordeeva, M.L. Kalaida, Cluster characterization of waters by their total antioxidant activity, 60 (10), 67-73 (2019)

15. I. Tadesse, F.B. Green, J.A. Puhakka, Seasonal and diurnal variations of temperature, $\mathrm{pH}$ and dissolved oxygen in advanced integrated wastewaterpond system treating tannery effluent, 38, 645-654 (2004)

16. P.V. Elorant, Physical and chemical properties of pond waters receiving warm-water effluent from a thermal power plant, 17, 133-140 (1983)

17. M.L. Kalaida, M.E. Gordeeva, Features of the physicochemical water state of reservoirs of energy facilities, IOP Conf. Series: Earth and Environmental Science, 288, 012051 (2019)

18. M.E. Gordeeva, R.V. Zanozeev, Modification of the temperature condition of the basin-cooler in the energy object coverage, IOP Conf. Series: Earth and Environmental Science, 288, 012040 (2019)

19. G. Kirillin, T. Shatwell, P. Kasprzak, Consequences of thermal pollution from a nuclear plant on lake temperature and mixing regime, 496, 47-56 (2013)

20. I. Kokaji, The present status for thermal discharge of nuclear power plant, 29, 413-420 (1995)

21. L. Encina, A. Rodriguez-Ruiz, C. GranadoLorencio, Distribution of common carp in a Spanish reservoir in relation to thermal loading from a nuclear power plant, 33, 444-450 (2008). 